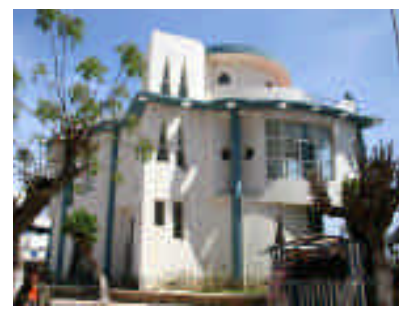

Casa de Cultura de M'diq. Imagen: Vigia Observatorio Cultural tural, convocando a quienes trabajarán en el mismo, a expertos y docentes en los numerosos aspectos que deberán tocarse: geógrafos, arquitectos, gestores culturales, metodólogos en investigación, informáticos, fotógrafos, historiadores del arte, gestores teatrales, etc. Un proceso formativo que nos daría al final la herramienta metodológica para obtener todos los datos precisos en la construcción del mapa. Al final lo que esperamos obtener son dos cosas: El Mapa de Equipamientos Culturales y Conocimiento. Esto último es probablemente tan importante como el mapa en sí mismo. Un segundo producto del proyecto es editar una publicación que recoja la metodologia seguida y todos los escollos encontrados en el mismo. En diciembre de este año está prevista la salida a la luz tanto del CD con los mapas como la publicación del método elaborado.

Todo puede ser visto como desde el umbral de un sueño. Y puede todo quedar de súbito borrado. Nos lo advertía Valente en las palabras que encabezan estas líneas. No le falta razón y no puedo concluir sin realizar dos advertencias. Sendas preocupaciones que me asaltan sobre el futuro. La primera es que un mapa de equipamientos no es más que una parte de

\section{Enséñame la necrópolis}

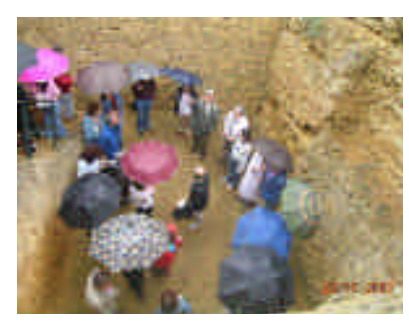

magen de uno de los momentos de la explicación de la tumba de Postumio de la Necrópolis de Carmona por el profesor Manuel Bendala Gal un mapa cultural genérico de un territorio. Nos habla y nos dice cosas de esos espacios, pero no lo dice todo. Precisamos cartografías añadidas, las que hablan de los creadores, de las tramas de relaciones, de las asociaciones, de los recursos, de todos los aspectos que conforman la realidad cultural. No es que nuestros mapas de equipamientos no tengan valor, es que nos están reclamando más trabajo, más esfuerzo, están demandando avanzar más en el trabajo. Por otro lado me preocupa la continuidad, o mejor dicho en el mantenimiento de unas bases de datos que no queden abandonadas minutos después de ser presentadas a los medios. Mantener los mapas en el tiempo de manera que en el transcurso de los años podamos ir observando la evolución de nuestros equipamientos. Ese es sin duda el gran reto. No sea que al final, como nos dice el poeta, concluyamos desesperados que todas las guías mienten.

J. Luis Ben

Vigia. Observatorio Cultural de la Provincia de Cádiz
La cantidad de visitantes del Conjunto Arqueológico de Carmona (CAC), Sevilla, parece estacionado en una banda que va de los treinta y dos a los treinta y cinco mil por año. En números absolutos, está por debajo de otros conjuntos arqueológicos más conocidos, y casi duplica las conocidas de otras instituciones dedicadas a la difusión del patrimonio histórico en la ciudad de Carmona. Sin embargo, es preciso analizar qué tipo de visitantes vienen y, sobre todo, cómo evalúan la visita y qué conocimiento, reflexión o mensaje hemos sido capaces de transmitirles.

El núcleo fundamental de usuarios está compuesto por visitantes organizados en grupos, escolares y turistas nacionales o extranjeros. Los pequeños grupos no organizados, así como los visitantes solos o en parejas, son poco representativos del total. En su comportamiento, sin embargo, son los que demuestran tener más interés y disponer de más tiempo para visitar el CAC, demandando mayor información. En conclusión, existe un amplio porcentaje de visitantes, cuyo nivel de comprensión de los vestigios es bastante bajo, y que, inciden de forma negativa en su conservación. Por eso se requiere una reflexión sobre el régimen de visitas al CAC, como parte fundamental de su gestión.

Se ha realizado un estudio sobre el grado de comprensión del mensaje transmitido a los visitantes a través del diseño museológico y museográfico del centro de interpretación, como primera fase para su reformulación. El reto no residiría tanto en incrementar el número de visitantes; habría que acometer estudios específicos sobre el grado de desgaste imputable a los visitantes en los principales conjuntos hipogeos de la necrópolis, así como realizar pequeñas obras de conservación, para restaurar lo ya deteriorado, junto a otras de mayor envergadura para diseñar itinerarios alternativos e infraestructuras explicativas suficientes que hagan innecesario bajar por sistema a todas las tumbas o recorrerlas en toda su integridad.

Resulta evidente que sea prioritario mejorar la calidad de la experiencia en la visita que promover un aumento del número de visitantes. Y dentro de esta estrategia se incluye la actividad "Enséñame la Necrópolis". Su propósito no es incrementar el monto de visitas, sino incentivar a que venga la población del entorno. Para ello, aprovechando la tradición de guiar visitas al CAC, se ha pedido a un grupo de personas de reconocido prestigio en el ámbito profesional, a políticos locales o de raigambre local, así como a otras personas vinculadas con el mundo de la cultura que ofrezcan su visión sobre el interés de los vestigios arqueológicos custodiados en el CAC o, de forma más simple, que hagan a los demás partícipes de su vivencia junto a este milenario monumento. De momento la acogida ha sido bastante buena, cifrándose la asistencia media en unas cuarenta personas. Esto nos anima a continuar con este proyecto durante el año que viene.

Ignacio Rodriguez Temiño Director del CAC 